\title{
Conflict between humans and elephants on private land in northern Kenya
}

\author{
Chris R. Thouless
}

\begin{abstract}
About 3000 elephants live in the Laikipia/Samburu region of northern Kenya - the largest remaining population outside the country's formal protected areas. The elephants occasionally kill or injure people, damage the crops of small-scale farmers, drive cattle away from water sources and cause a range of other problems for the human population. As a result, a number of elephants have been shot for control purposes in recent years and others have died as a result of poisoning, snares or spearing. The author examines the conflict between elephants and humans in areas of differing land use and makes suggestions for resolving at least some of the problems.
\end{abstract}

\section{Introduction}

African elephant populations have been reduced substantially in the past 20 years. The impact of poaching for ivory has been well described (Douglas-Hamilton, 1987). However, even in the absence of commercial poaching, elephant numbers have declined in some areas of increasing human density. It is assumed that the main cause has been the conflict between elephants and humans for resources, particularly arable crops (Parker and Graham, 1989), but little is known about the ways in which this conflict affects elephant populations. Elephants may change their range in response to disturbance (Barnes et al., 1991), or there may be additional sources of mortality, such as control shooting by game departments, or snaring, which result in a gradual decline in numbers (Haigh et al., 1979).

An understanding of the conflict between elephants and humans is important for conservation. If they are to coexist, the levels of conflict must be reduced, by decreasing the costs and increasing the benefits that come to people from the presence of elephants. However, only by understanding the nature and extent of conflict under different circumstances can one determine whether coexistence is possible, and at what cost.
This paper describes the forms of conflict between elephants and humans in the range of the Laikipia/Samburu elephant population in northern Kenya. This is the largest remaining population in Kenya outside formal protected areas, consisting of about 3000 animals. Over the last 30 years its range has expanded southwards from semiarid pastoral areas in Samburu District (Figure 1) into large-scale private ranches and adjoining settlement areas in Laikipia District.

\section{Land use in Laikipia and Samburu}

During colonial times most of Laikipia consisted of cattle ranches. After independence in 1963, ranches in the south of the district were bought for settlement schemes and subdivided into $0.5-2$-ha farms. Initially these were confined to areas of high agricultural potential but with an increasing human population, more arid regions were settled.

The unplanned nature of subdivision meant that some settlement schemes were surrounded by ranches supporting substantial wildlife populations. The poor quality of much of the land meant that many plots were left unoccupied and, at the limits of settlement, farms were surrounded by large areas of bush (Kohler, 1987). In these areas human densities 


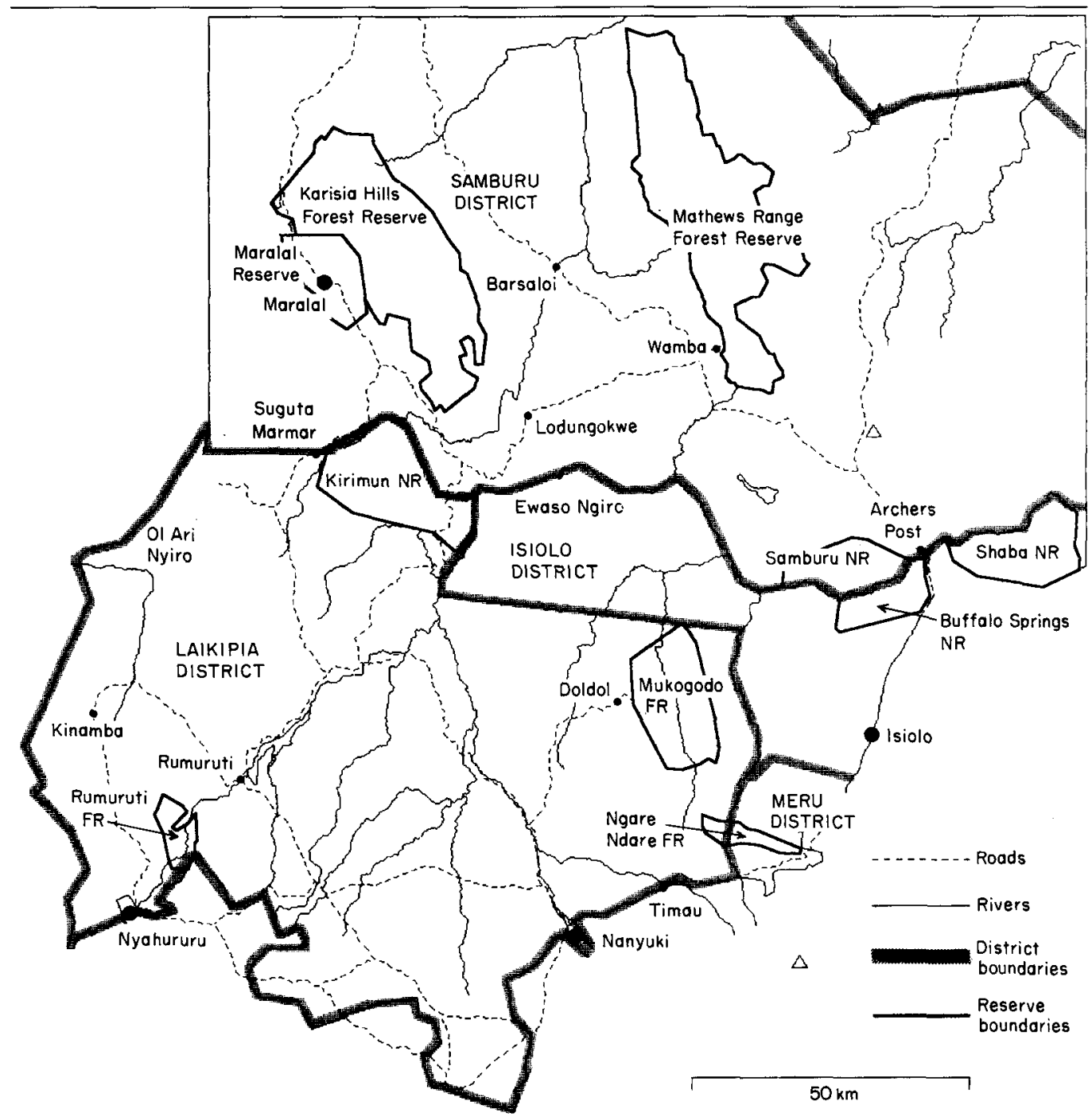

Figure 1. Laikipia/Samburu elephant range showing district boundaries, roads, reserves and centres of human population. NR, National Reserve; FR, Forest Reserve.

are as low as $25-50$ people per sq $\mathrm{km}$, compared with 200-300 people per sq $\mathrm{km}$ in the areas of high agricultural potential (Kabuage et al., 1991).

Cattle ranches, the majority of which are larger than 5000 ha, still account for much of Laikipia District (Figure 2). Human densities on the ranches are very low, usually about one person per sq $\mathrm{km}$. There are cattle on all the ranches, but the economic constraints operating on them differ. Some are commercial operations providing the only source of income for their owners, while others are maintained for aesthetic reasons. These differences affect the owners' attitudes towards elephants and other wildlife. Elephants occur throughout the ranching areas, except on properties which have been fenced to exclude them or to protect rhinos.

The northern part of the range of the elephants lies in semiarid pastoralist areas in Samburu and Isiolo Districts. There are resident populations in the forest reserves of the Mathews Range and the Karisia Hills, and in 


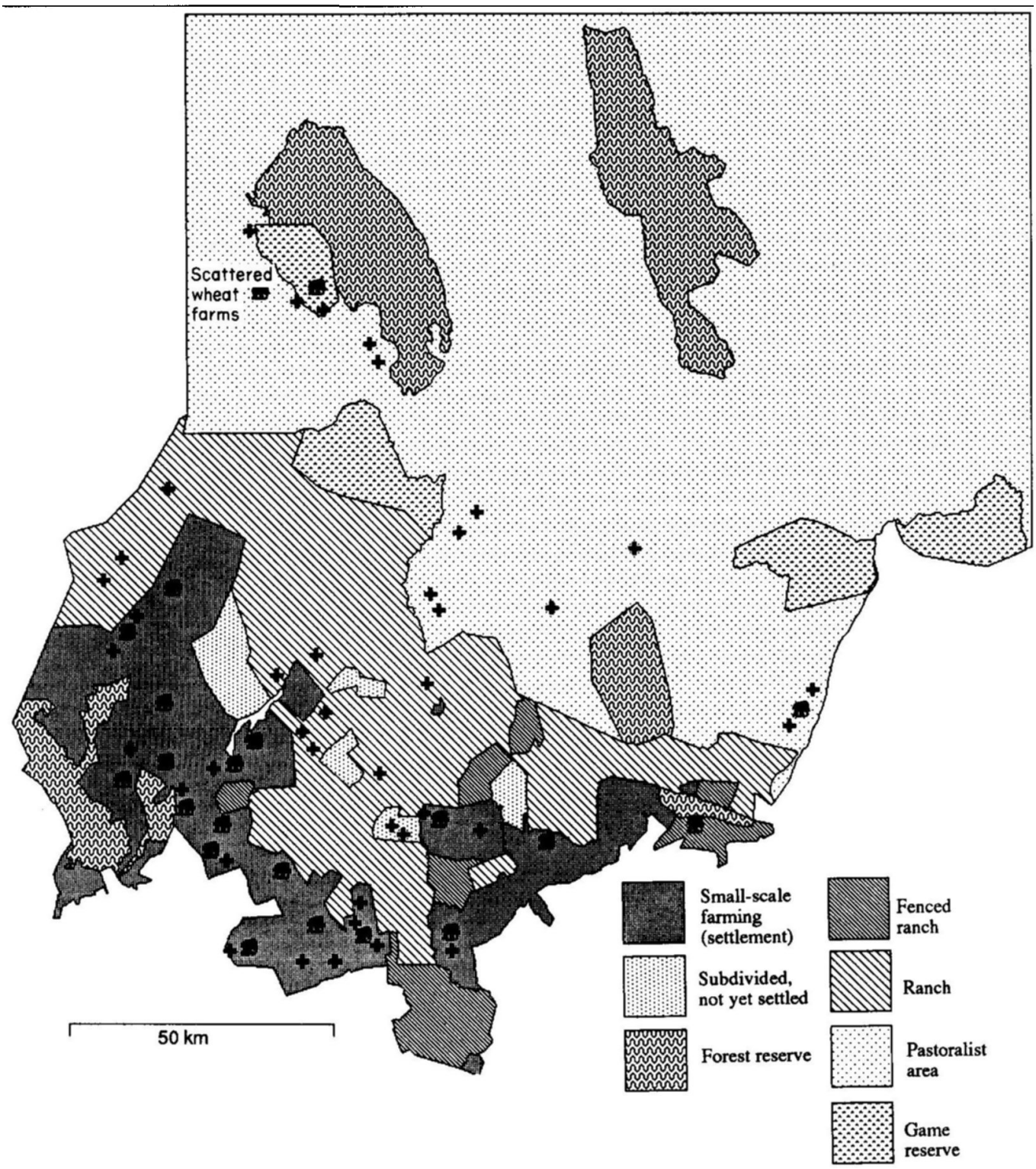

Figure 2. Laikipia/Samburu elephant range showing land use. Elephant symbols indicate main crop-raiding problem areas and crosses show locations of recorded human deaths and injuries from 1989 to 1992. Land-use map boundaries from Kohler (1987).

Samburu and Buffalo Springs National Reserves. After the rains elephants from Laikipia move into pastoralist areas to the south of the Ewaso Ngiro, and south and east of the Mathews Range. Most of Samburu and Isiolo is either land held in trust by the District Council or has been divided into group ranches. Although in some areas heavy grazing by livestock has resulted in a reduction of wildlife numbers, other areas have substantial populations of elephants and other species. Typical human population densities are in the region of 10 per sq $\mathrm{km}$. 


\section{Methods}

The main sources of information for this paper were Kenya Wildlife Service (KWS) records. In each district there is a central game station manned by KWS wardens and rangers, and there are usually a number of substations and outposts. Each station or outpost has a report book (RB) and/or occurrence book (OB), in which information brought in by members of the public and actions taken by KWS staff are recorded. In addition to information gathered from RBs and OBs, KWS monthly and annual reports, ivory store records, ranch monthly reports, information collected on site and radio messages sent to KWS Headquarters were used. The figures given are the result of crossreferencing these different data sources.

\section{Economic damage caused by elephants}

\section{Settlement areas}

The main economic damage inflicted by elephants in the settlement areas was the destruction of crops. Although other wildlife species - zebra, buffalo, hartebeest, porcupines and bush pigs - damaged crops, elephants were the most widely feared because of their ability to eat and trample huge quantities of crops in a single night, the difficulty of stopping them with any barrier, and the danger they posed to human life.

Elephants ate most kinds of crops grown in the area. Maize is the staple crop, and damage to maize accounted for 45 per cent of complaints at the Rumuruti Station $(n=216)$. Other major crops taken were beans (13 per cent), wheat (11 per cent), potatoes (5 per cent) and bananas ( 5 per cent). Elephants also ate sugar cane, millet, pumpkins, wild spinach, onions, tomatoes and carrots, and damaged orange trees and other fruit trees. In Samburu there is little cultivation except around Maralal, where elephants damaged the extensive wheat fields.

Crop raiding by elephants took place in all but the most densely settled farming areas in Laikipia, although it was most severe on farms

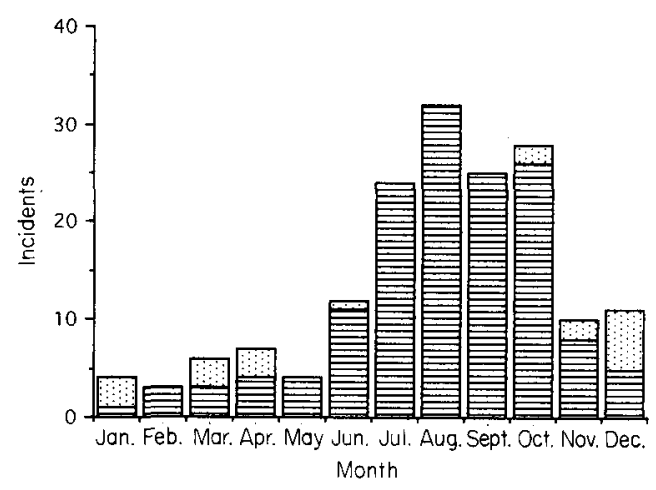

Figure 3. Crop raiding complaints at Rumuruti Station 1990-92. Stipled areas, grain stores; hatched areas, growing crops.

next to unfenced ranch boundaries. It took place throughout the year but was most intense when the crops were close to being harvested, usually in August-September (Figure 3). Early in the season elephants pulled up young maize shoots and, once the cobs were formed, used their trunks to strips cobs and leaves from the stalks. Bull groups did most of the raiding, but during the peak of the season, cows and calves joined them. Groups of elephants spent the day close to the edge of the ranches, in swamps or in areas of dense bush within the settlement areas, and moved into the farms after dark.

Farmers used a variety of methods to protect their crops - erection of human effigies, construction of twig and barbed wire fences, making noise and using fires and spotlights. Although some methods were effective in deterring other crop-raiding animals, none worked for elephants. When possible, game rangers tried to deter raiding elephants by firing shots in the air or even by firing with shot guns at their rumps, but this usually just resulted in the elephants moving to neighbouring farms.

Assessing the direct economic costs of crop raiding is difficult, because one has to calculate the projected crop yield in the absence of elephants. Often people will harvest maize early (because the rate of attack is greatest on mature cobs), and this reduces the value of the harvest, even if elephants do not eat it. On the 
A maize store damaged by elephants (C. R. Thouless).

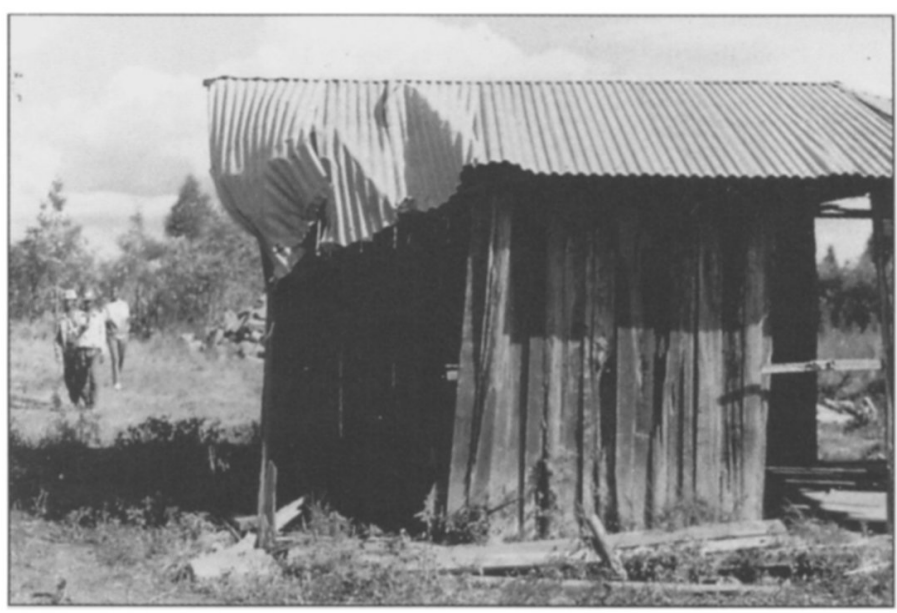

other hand, because of the uncertain weather in Laikipia, entire crops may wither and die during the growing season, and damage done early in the season by elephants would have no impact on the final harvest.

Irigia (1990) carried out an assessment of the economic damage caused by elephants in settlement areas next to Ol Ari Nyiro Ranch in western Laikipia (Figure 1). Human densities ranged from 50 to 150 people per sq $\mathrm{km}$ (Kabuage et al., 1991) with farms between 0.5 and 2 ha, surrounded by bush. Out of 2957 farms, 105 were assessed and damage was estimated at between 10 and 24 per cent of the total maize crop in the four subdivisions of the study area. The highest damage was in sparsely settled areas; on the heavily settled areas to the south of Ol Ari Nyiro Ranch, the damage was less. The value of the lost crops on the surveyed farms was more than KSh100,000 (\$US33,000). Elephants also damaged beans, bananas, potatoes and tree seedlings and broke into grain stores after the harvest. They broke open 15 stores during November 1990, and totally destroyed two.

There were additional indirect costs incurred by the need for people to spend sleepless nights while waiting to defend their crops from raiding animals. In extreme cases children were unable to attend school because their parents required their assistance in chasing off animals.

\section{Ranches}

When large numbers of elephants first moved into Laikipia in the 1970s, the most vocal complaints came from ranchers who had invested in fencing and water supplies. Damage mainly occurred through destruction of wire fencing, damage to dam walls, drinking troughs, tanks and piping; also the presence of large numbers of elephants was a physical hazard to stock and herders.

However, over the past 10 years ranchers have learnt either to live with elephants or to exclude them with electric fencing. Some wellmaintained electric fences of simple design have proved effective. There are still problems on ranches where the perimeter fencing is incomplete, where maintenance is inadequate, and where crops are being grown in irrigation schemes, providing a powerful incentive to the elephants. On ranches where the presence of elephants is accepted, fenced paddock systems have had to be abandoned and cattle are managed in a more traditional way, protected by herdsmen and corralled at night. Livestock killing by elephants is a minor problem compared with that by lions; elephants were reported to have killed six cows and a sheep in 1992. Several ranchers have developed tourism as a major income source and recognize the presence of elephants as an asset. 
Table 1. Human deaths and injuries in Laikipia caused by elephants, 1989-1992

\begin{tabular}{lllll}
\hline & 1989 & 1990 & 1991 & 1992 \\
\hline Deaths & 2 & 3 & 4 & 13 \\
Injuries & 3 & 3 & 5 & 6 \\
Total & 5 & 6 & 9 & 19 \\
\hline
\end{tabular}

\section{Pastoralist areas}

The main conflict between elephants and people in the pastoralist areas is over access to water. The Ewaso Ngiro and a few streams emerging from the mountain forests are the only permanently flowing water sources. After the rains there are many temporary pools, but once these dry up humans and wildlife must use wells dug in the bed of sand rivers, and a small number of dams and springs. The main consequences of elephants and cattle attempting to use the same water sources simultaneously are that cattle get chased away, and some are killed. In 1992 there were reports of six cows, three goats and six sheep killed by elephants in the pastoralist part of Laikipia, although the true figure must have been higher, because there is no compensation for such losses and reporting is difficult. In thick bush country elephants present a danger to people who are walking and herding, and on occasion people have stopped sending their children to school because of the risk involved in walking from their homes to the school.

\section{Human deaths and injuries}

The number of people killed and injured by elephants in Laikipia District has increased in the last few years (Table 1). The exceptionally high number in 1992 may have been partly caused by drought conditions, which resulted in elephants staying in well-watered southern areas close to human settlements. Although most of the deaths and injuries recorded from Laikipia occurred in settlement areas rather than on ranches or in pastoralist areas, the incidence per head of human population was highest on ranches (Table 2). Numbers of reported injuries and deaths in the other districts of Samburu and Isiolo were lower, with a total of nine deaths and 13 injuries recorded over 4 years, although this is probably a consequence of incidents being less likely to be reported. As a proportion of the population at risk, this was similar to the figure for the pastoralist areas of Laikipia.

The relatively low number of incidents in

\begin{tabular}{|c|c|c|c|c|}
\hline & Settlement & Ranches & Pastoral & $\begin{array}{l}\text { Other/ } \\
\text { unknown }\end{array}$ \\
\hline Deaths & 10 & 8 & 1 & 2 \\
\hline Injuries & 10 & 5 & 2 & 1 \\
\hline Total & 20 & 13 & 3 & 3 \\
\hline $\begin{array}{l}\text { Approx. } \\
\text { human } \\
\text { population } \\
\text { Total deaths/ } \\
\text { injuries per } \\
1000 \text { people } \\
\text { per annum }\end{array}$ & 80,000 & 4,000 & 10,000 & \\
\hline
\end{tabular}

Table 2. Human deaths and injuries caused by elephants in different land-use areas in Laikipia in a 4-year period, 1989-1992
Approximate human populations at risk calculated from 1989 census figures for pastoralist and settlement areas (Kabuage et al., 1991).

Figures include all inhabitants of pastoralist areas and settlement areas where crop-raiding by elephants took place. Human population figure for ranches is maximum estimate. 


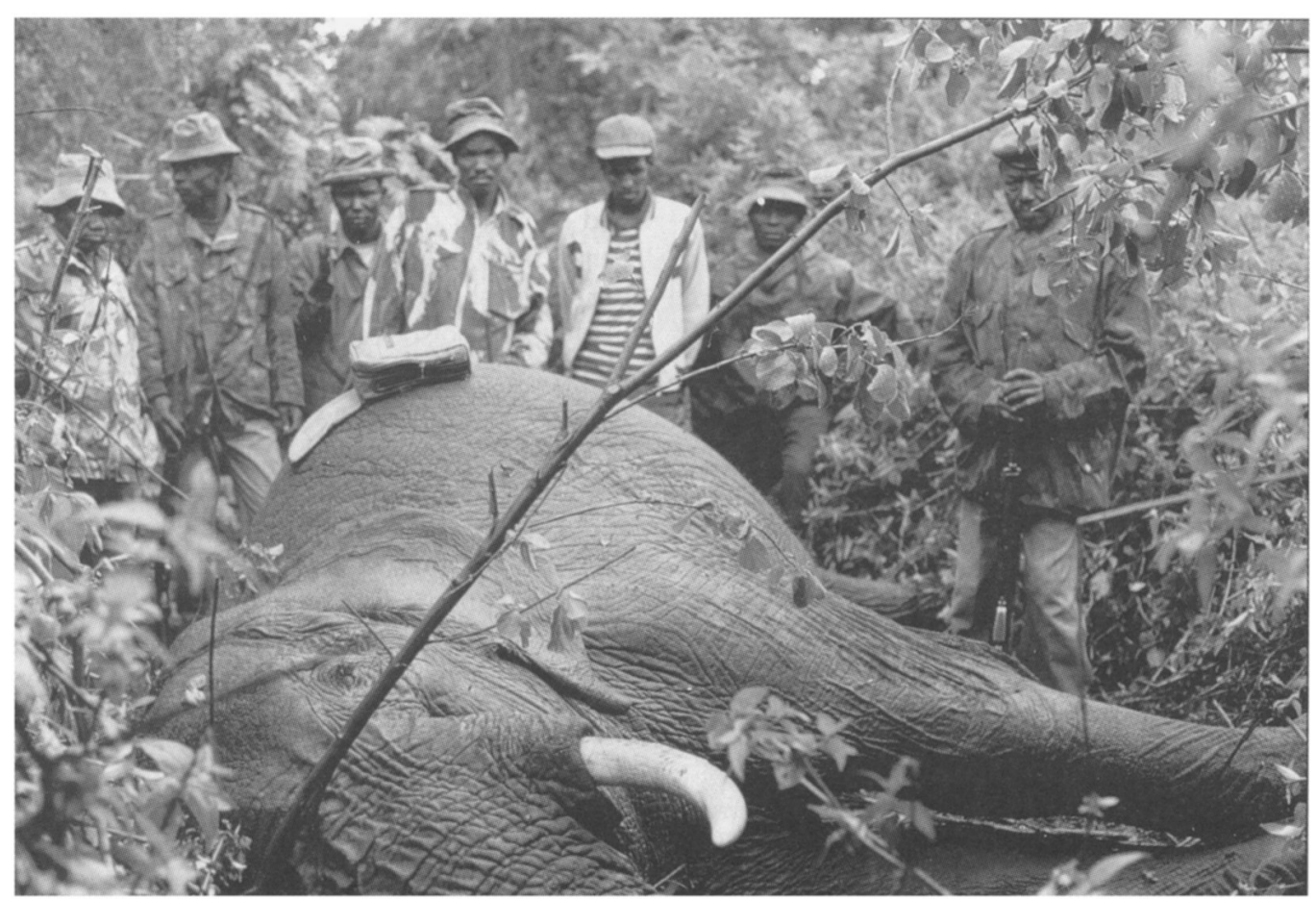

An elephant shot on a control operation (I. Craig).

settlement areas was surprising, given the high human population and how widely the elephants ranged (Table 2, Figure 2). This may be because elephants coming on to farms at night had little to fear from farmers attempting to defend their crops, especially since a high proportion of the crop raiders were bulls. Groups of elephants on ranches usually included cows with young calves, which were more likely to feel seriously threatened by the proximity of a human.

Other circumstances in which people have been killed or injured by elephants include herding livestock (four cases), harvesting crops in daylight (one case), collecting firewood (one case), riding a bicycle (the rider was badly injured and the bicycle destroyed) and walking through the bush (five cases). In two cases the victim was known to be drunk and was probably unaware of the proximity of the elephants. Two men died on a ranch immediately after it had been sold for settlement, when they were walking through the bush to peg out the boundaries of their farm plots.
Little information is available on the types of elephants responsible for attacks on humans, although they are known to include both bulls and cows. Sometimes attacks are attributed to particular individuals, usually bulls, which become known in an area for their bad temper. Some females, particularly those with young calves, will charge on sight. Although these charges are not generally pursued over any great distance, anyone stumbling into the middle of a herd, particularly at night, would find it difficult to get away in time to avoid being trampled.

\section{Elephant deaths and injuries}

Table 3 shows recorded elephant deaths in the range of the Laikipia-Samburu population over 3 years. The number of elephants shot on control has increased, largely in response to the increasing number of humans killed by elephants. There has been a decline in the number of elephants illegally killed for ivory, be- 
Table 3. Reported elephant deaths from the Laikipia-Samburu population

\begin{tabular}{lrrr}
\hline Cause & 1990 & 1991 & 1992 \\
\hline Unknown/natural/accident & 10 & 31 & 26 \\
Illegally killed* $_{\text {Controlt }}$ & 19 & 16 & 20 \\
Total & 9 & 12 & 22 \\
\hline
\end{tabular}

* Illegally killed: includes speared animals that have had to be put down because of spear wounds that would have resulted in death.

+ Control: elephants killed by KWS or land-owner in defence of life or property where ivory was handed over and death reported.

Table 4. Methods used in illegal killing

\begin{tabular}{lrrr}
\hline & 1990 & 1991 & 1992 \\
\hline Speared & 4 & 10 & 12 \\
Shot & 15 & 4 & 4 \\
Snared & 0 & 0 & 2 \\
Unspecified & 0 & 2 & 2 \\
Ivory removed & 14 & 5 & 6 \\
Ivory not removed & 5 & 11 & 14 \\
\hline
\end{tabular}

cause of the improved security situation and decline in local demand for ivory. This is shown by the reduction in the number of shot elephants and in the number of carcasses found with the tusks removed (Table 4). The most recent case of killing by organized gangs with automatic weapons was in late 1990 .

Most of the illegal killing in 1992 was done by pastoralists spearing elephants. Often the speared elephants did not die immediately, but a considerable time later, when their wounds had become infected. There are a number of reasons for spearing elephants. In several cases cattle herders speared elephants in conflict over water sources, because they stampeded cattle, killed them, prevented them from getting to water, or broke down wells dug in sand rivers. Two spearings were said to have been done to get ivory for ritual purposes, and one elephant was reported to have been speared in 'revenge' for a woman who was killed by elephants.

It is difficult for the small-scale farmers to kill elephants because they do not have a tradition of hunting large animals. However, two elephants were found dead in the settlement areas close to Ol Ari Nyiro Ranch in 1991 without external injuries, shortly after there had been talk of poisoning elephants. A number of people were taken to hospital after eating the flesh of one of these animals and it is likely that poisoned corn cobs were left for them.

Two elephants have had to be put down because of injuries caused by snares. This may become an increasing problem as local people suffer more from food shortages and rely more on snaring of antelope. In 1992 at least seven elephants were seen with severely swollen legs because of snares caught around them. Some may have been unable to recover from these injuries.

\section{Discussion}

Conflict between elephants and humans is an important issue in Laikipia District, especially in the farming areas, where elephants are responsible for damaging crops and killing people. The :lephants seem to suffer little from the conflict, with no indication of avoidance of conflict areas, and little mortality, except from bulls killed on control (only three out of 23 where the sex was recorded were females). The problem is exacerbated by the fact that these areas are next to large-scale ranches, with very low human densities, where there is little conflict and elephants are tolerated and even encouraged.

Because of the proximity of farms to areas of high elephant density, the only effective way of reducing conflict appears to be the construction of elephant-proof barriers. There are plans to build a fence along the entire settlement-ranch boundary, once a land-use policy is agreed upon, and issues of design and maintenance are resolved. Several sections have already been built, with variable effectiveness.

In pastoral areas there is some loss of human life, and livestock, and inconvenience caused by competition for water, but overall 
the problems caused to people by elephants are far less than in the settlements. Elephants, however, are affected more by the conflict. There is some evidence that movements away from pastoral areas in the dry season towards the ranches are dictated by competition over water (Thouless, in prep.). The attraction of the ranches is hardly surprising, because ranches have higher rainfall than the pastoral areas, combined with much lower human densities.

Recorded elephant deaths caused by humans are low compared with the total elephant population, but it is possible that these are significant, because elephant populations are very sensitive to increases in adult female mortality. It has been calculated that in Amboseli National Park, an additional adult female mortality of 2 per cent per annum would be sufficient to reduce the population by 50 per cent over 45 years (C. Moss and A. Dobson, pers. comm.). Although recorded illegal killings only accounted for about 0.7 per cent of the total Samburu/Laikipia elephant population in 1992, the majority of animals killed appeared to be adult females (eight out of nine known cases of spearing). In addition, in such a large area it is probable that only a small proportion of illegal killings were reported.

Reduction of the level of conflict in the pastoral areas may be possible if some benefit to the local people can be derived from the presence of the elephants. It has been suggested that additional water points could be built, but solving problems over access to water in dry areas may only create new ecological problems, as a result of exposing additional areas to heavy grazing pressure. Further development of low-impact high-cost tourism, and perhaps the introduction of safari hunting, offer the best possibilities, but any development programme will need to be carefully designed in conjunction with the local people, with the understanding that providing revenue from wildlife is only an uncertain first step towards effective conservation.

\section{Acknowledgments}

This work was funded by World Wide Fund for Nature-International and was carried out on behalf of the Kenya Wildlife Service Elephant Programme under Joyce Poole. My thanks are due to other members of the Laikipia Elephant Project, Bernard Kaaria and Martin Mulama, to the District Wardens of Laikipia, Mr Muthamia and Mr Gichure and the District Warden of Samburu District, Mr Munyugi and their staffs, and to the managers of Laikipia Ranching, Mr Francombe and Mr Heath and the manager of Mpala Ranch, Mr Wreford Smith, as well as many other Laikipia ranchers, for hospitality and access to their records. Project advisers Dr lain Douglas-Hamilton for the Gallmann Memorial Foundation, and Dr Holly Dublin of the WWF East African Regional Office have provided support and encouragement. Phyllis Lee provided valuable comments on an earlier version of the manuscript.

\section{References}

Barnes, R.F.W., Barnes, K.L., Alers, M.P.T. and Blom, A. 1991. Man determines the distribution of elephants in the rain forests of northeastern Gabon. Afr. J. Ecol. 29, 54-63.

Douglas-Hamilton, I. 1987. African elephants: population trends and their causes. Oryx, 21, 11-23.

Haigh, J.C., Parker, I.S.C., Parkinson, D.A. and Archer, A.L. 1979. An elephant extermination. Environmental Conservation, 6, 305-308.

Irigia, B.K. 1990. Elephant Crop Raiding Assessment in Ngarua Division of Laikipia District. Unpublished report to the Kenya Wildlife Service.

Kabuage, S.I., Leibundgut, C., Mozer, T. and Wiesmann, U. 1991. Water Development Plan for Laikipia District, Kenya. Ministry of Reclamation and Development of Arid, Semi-arid and Wastelands, Nairobi.

Kohler, T. 1987. Land use in transition. Aspects and problems of small-scale farming in a new environment: the example of Laikipia District, Kenya. Geographica Bernensia. African Studies Series A5.

Parker, I.S.C. and Graham, A.D. 1989. Elephant decline (Part I): downward trends in African elephant distribution and numbers. Intern. $J$. Environmental Studies, 34, 287-305.

Chris Thouless, Kenya Wildlife Service, PO Box 40241, Nairobi, Kenya and WWF Regional Office for East Africa, PO Box 62440, Nairobi, Kenya. (Present address: Environment and Development Group, 13 St Giles, Oxford OX1 3JS, UK.) 